\title{
POINT: Operative risk of pneumonectomy-Influence of preoperative induction therapy
}

\author{
Henning A. Gaissert, MD, Dong Yoon Keum, MD, Cameron D. Wright, MD, Marek Ancukiewicz, PhD, \\ Eric Monroe, BS, Dean M. Donahue, MD, John C. Wain, MD, Michael Lanuti, MD, James S. Allan, MD, \\ Noah C. Choi, MD, and Douglas J. Mathisen, MD
}

Background: Prior data indicate increased perioperative morbidity and mortality in patients receiving induction chemoradiotherapy before pneumonectomy for lung cancer.

Objective: We reviewed a consecutive series of pneumonectomies to determine the impact of induction therapy on operative mortality.

\begin{abstract}
Results: Over a 15-year period, 183 patients underwent pneumonectomy for lung cancer. Forty-six received combined preoperative radiochemotherapy $(25.2 \%)$, and 137 patients underwent resection only. Indications for induction therapy were stage IIB disease in 1 , IIIA in 35 , IIIB in 8 , and IV in 2 patients. Patients receiving induction therapy were younger (mean age 58.4 vs 61.9 years; $P=.033$ ), had less heart disease (6.5 vs $26.3 \% ; P=.0035)$, higher preoperative forced expiratory volume in 1 second ( 2.48 vs $2.13 \mathrm{~L} ; P=.0018$ ), a lower rate of endobronchial tumor (34.8 vs $67.2 \% ; P=.0002)$, and underwent intrapericardial procedures more often (71.7 vs $43.1 \% ; P=.0011)$. Hospital mortality was $4.3 \%(2 / 46)$ after preoperative therapy and $6.6 \%(9 / 137)$ after resection only $(P=.73)$; the difference in cardiopulmonary morbidity was not significant $(51.1 \%$ vs $40.4 \%$; $P=.22)$. Induction did not predict hospital mortality after adjustment for a propensity score derived from nonoperative and operative variables correlated with neoadjuvant therapy.
\end{abstract}

Conclusions: A regimen of induction radiation and chemotherapy does not increase the operative mortality of pneumonectomy in carefully selected patients.

As the most extensive anatomic lung resection, pneumonectomy has the highest operative mortality. The administration of preoperative adjuvant therapy before pneumonectomy is controversial because of the potential to increase this risk. Trimodality therapy was, for example, associated with high mortality in a phase II multi-institutional prospective randomized trial, particularly for right-sided procedures. ${ }^{1}$ Conversely, patients with locally advanced lung cancer stand to receive the greatest benefit of additional up-front tumor therapy, and limiting patients with large tumors and $\mathrm{N} 2$ disease to surgical resection first risks progression to systemic disease.

$\mathrm{We}^{2}$ have used combined radiotherapy and chemotherapy for the preoperative treatment of N2 disease and selected other indications since the late $1980 \mathrm{~s}^{2}$ and reviewed our experience during a period of consistent application of

\footnotetext{
From the Division of Thoracic Surgery and Department of Radiation Oncology, Massachusetts General Hospital and Harvard Medical School, Boston, Mass.

Read at the Eighty-eighth Annual Meeting of The American Association for Thoracic Surgery, San Diego, Calif, May 10-14, 2008. Presented as part of the Point/Counterpoint Session in General Thoracic Surgery.

Received for publication May 12, 2008; revisions received Oct 1, 2008; accepted for publication Nov 15, 2008.

Address for reprints: Henning A. Gaissert, MD, Massachusetts General Hospital,

Blake 1570, Fruit Street, Boston, MA 02114 (E-mail: hgaissert@partners.org).

J Thorac Cardiovasc Surg 2009;138:289-94

$0022-5223 / \$ 36.00$

Copyright (c) 2009 by The American Association for Thoracic Surgery

doi:10.1016/j.jtcvs.2008.11.069
}

neoadjuvant radiochemotherapy to examine mortality and its predictive factors.

\section{METHODS}

Medical records of a consecutive series of patients with lung cancer undergoing pneumonectomy by the Division of Thoracic Surgery at Massachusetts General Hospital were reviewed. Complex procedures were excluded as outlined in Figure 1. The Partners Human Research Committee approved the study. Demographic data, preoperative pulmonary function, and scintigraphic ventilation-perfusion data were obtained. Comorbid conditions were recorded. Hypertension was defined as taking antihypertensive medication to lower blood pressure, diabetes mellitus as taking oral or parenteral medications to lower blood sugar, and congestive heart failure as past hospital admissions at any time or taking diuretics or angiotensin-converting enzyme inhibitors for this diagnosis or having symptoms related to reduced left ventricular ejection fraction. Coronary artery disease was defined as a past myocardial infarction or evidence of myocardial ischemia by electrocardiogram or stress testing or known stenosis after cardiac catheterization. Renal failure was defined as a creatinine level above $1.6 \mathrm{mg} / \mathrm{dL}$ and peripheral vascular disease as the presence of symptoms of claudication or past surgical or catheter-based intervention for this indication. The diagnoses of cerebrovascular accident or transient ischemic attack were assumed after permanent or temporary focal neurologic deficits. Patients underwent computed tomography (CT) of the chest, evaluation of the brain by either CT or magnetic resonance imaging, and either bone scan or, since its inception, positron emission tomography. With the exception of patients referred to Massachusetts General Hospital after combined induction, all patients were evaluated by a thoracic surgeon before treatment, almost always including mediastinoscopy. No mediastinoscopy was repeated after induction therapy; restaging occurred with CT.

Neoadjuvant preoperative treatment consisted of combined chemotherapy and radiation. There was no uniform protocol during the study period, 


\section{Abbreviations and Acronyms}

$\mathrm{CT}=$ computed tomography

$\mathrm{FEV}_{1}=$ forced expiratory volume in 1 second

and numerous patients were treated at outside institutions; however, the standard preoperative radiation dose was administered in 25 fractions over a period of 5 weeks, in combination with chemotherapy, limiting the dose to the main bronchus to $45 \mathrm{~Gy}$. We have used a higher radiation dose (54 Gy) in selected extensive tumors. Some patients were referred after neoadjuvant therapy having received doses in excess of $60 \mathrm{~Gy}$. At Massachusetts General Hospital, there was a change from 2- to 3-dimensional conformal radiotherapy in 2001. Patients with prior cervical or mediastinal radiation for other indications were excluded.

The perioperative management was standardized regarding routine use of epidural catheters, intravenous fluid restriction, operative use of vasoactive drugs, and low tidal volumes during 1-lung anesthesia. A chest catheter was placed at the conclusion of the operation in all patients and removed either immediately after extubation or the next day. Intraoperative parameters studied were total duration, blood loss, transfusion requirement, epidural pain control, intraoperative hypotension, and operating room extubation.

Postoperative variables examined were reintubation, adult respiratory distress syndrome, pneumonia, pulmonary embolism, pulmonary edema, empyema, bronchopleural fistula, myocardial infarction, atrial fibrillation, ventricular fibrillation, congestive heart failure (grouped as major cardiopulmonary events), duration of mechanical ventilation, tracheostomy, reoperation, deep vein thrombosis, neurologic complication, and gastrointestinal complication. The hospital mortality was determined.

Tumors were staged according to published revisions of the international lung cancer staging system. ${ }^{3}$ The resection was complete if specimen margins, including bronchial, vascular, and soft tissue margins, were found to be free of tumor.

\section{Statistical Analysis}

Univariate analysis was conducted by Fisher's exact test for binary variables and the Wilcoxon exact test for continuous variables. The variables selected for calculation of a propensity score ${ }^{4}$ included all nonoperative and operative variables correlated with induction therapy or mortality in univariate analyses (except for highly correlated measurements, for example, forced expiratory volume in 1 second $\left(\mathrm{FEV}_{1}\right)$ and forced vital capacity, when only one was used).
The propensity score was calculated as follows:

$p=\exp (L) /(1+\exp [L])$

Where $\mathrm{L}$ is a linear function:

$L=-7.106461+0.008476$ age $-0.290960 l 1+0.19304 l 2-0.152798$

$13-2.096960 l 4-1.513946 l 5+1.015116 \mathrm{pN}$ classifier $-0.797669 \mathrm{pT}$ classifier $+0.687062 \mathrm{FEV}_{1}+0.035041 \mathrm{DLCO} \%+0.400145 \mathrm{l} 6+0.023664 \mathrm{l} 7$ $+1.580099 l 8+1.85461919+1.995547110+0.917844$ RBC packs

$l 1=1$ if male sex, 0 otherwise

$12=1$ if renal disease present, 0 otherwise

$13=1$ if hypertension present, 0 otherwise

$14=1$ if CAD or CHF present, 0 otherwise

$15=1$ if bronchial tumor mass present, 0 otherwise

$16=1$ if $\mathrm{FEV}_{1}$ is missing, 0 otherwise

$17=1$ if DLCO $\%$ is missing, 0 otherwise

$18=1$ if intrapericardial procedure, 0 otherwise

$19=1$ if beta-blockers were used during operation, 0 otherwise

$110=1$ if extubation after operation was immediate, 0 otherwise.

$\mathrm{CAD}=$ coronary artery disease; $\mathrm{CHF}=$ congestive heart failure; DLCO $=$ carbon monoxide diffusion capacity; $\mathrm{FEV}_{1}=$ forced expired volume in 1 second; absorbed radiation dose; $\mathrm{RBC}=$ red blood cell; $\mathrm{T}, \mathrm{N}=\mathrm{TNM}$ classifier; $\mathrm{pT}, \mathrm{pN}=$ pathologic $\mathrm{T}$ resp. $\mathrm{N}$.

The coefficients in the above linear function are maximum likelihood estimates obtained by logistic regression.

To determine whether induction therapy predicted hospital mortality, we used the propensity score as a variable in a logistic regression along with induction therapy.

\section{RESULTS}

From September 1993 to December 2007, 183 consecutive patients underwent pneumonectomy for non-small cell carcinoma of the lung at Massachusetts General Hospital. Their mean age was 61.1 years and $114(62.3 \%)$ were male. Comorbidity was present in $109(59 \%)$ patients: hypertension in $43 \%$, coronary artery disease or congestive heart failure in $21 \%$, diabetes mellitus in $7.7 \%$, and steroid use in $6.0 \%$. Eleven patients had received oral steroid therapy, 9 for reactive airway disease, 1 for radiation pneumonitis, and 1 after liver transplantation. Table 1 lists demographics and preoperative

Pneumonectomy for primary lung cancer, all types: 260 patients

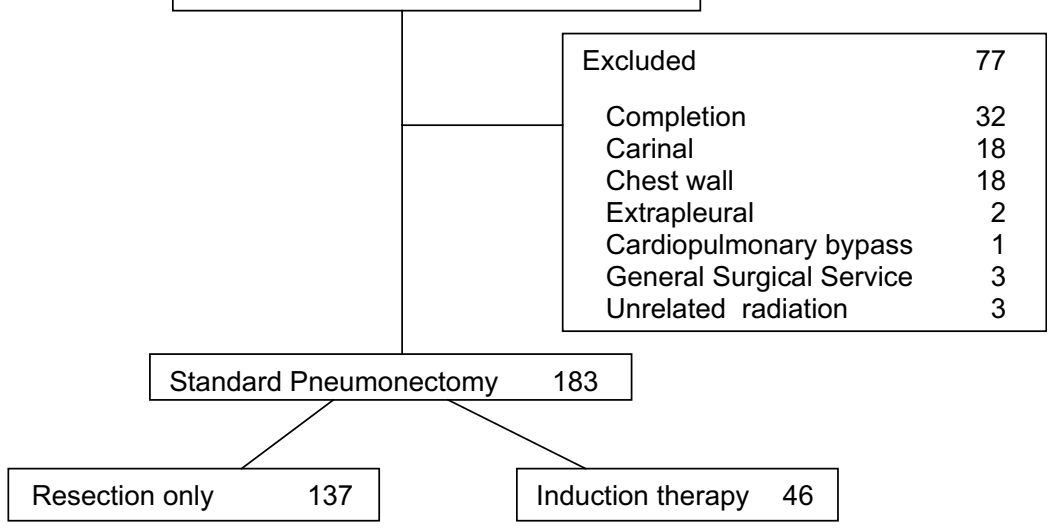

FIGURE 1. Composition of study group and excluded patients. 
parameters for patients with and without preoperative therapy. Patients receiving preoperative treatment were younger, had fewer cardiac comorbidities, and had better lung function. Mediastinoscopy preceded resection in $96 \%$ of patients.

\section{Preoperative Therapy}

Forty-six $(25.1 \%)$ of 183 patients received combined mediastinal radiation and chemotherapy. The clinical stage of patients treated with induction therapy was IIB in 1, IIIA in 35, IIIB in 8 (T4 in 2, N3 in 6), and IV in 2 patients. The chemotherapy regimen was cisplatinum/vinorelbine/5fluorouracil in 20 patients, carboplatin/taxol in 17, cisplatinum/VP16 in 4, cisplatinum/taxol in 1, cisplatinum/VP16/ taxotere in 1, and was not recorded in 3. Complications of chemotherapy occurred in 11 patients, including neutropenia in 5 , pneumonia in 3 , and severe nausea in 3 . The median radiation dose was 45 Gy (range 42-72 Gy), but preoperative therapy rarely exceeded 54 Gy. Radiation was complicated by pneumonitis in 3, esophagitis in 7 , and important dysphagia in 2 patients.

\section{Resection}

In the induction group, 24 patients underwent left and 22 right pneumonectomy, whereas no neoadjuvant therapy was given to 52 having right-sided and 85 having left-sided resections. Table 2 lists operative parameters. Patients receiving induction had a higher proportion of intrapericardial procedures, required a greater number of transfusions, were more likely to receive beta-blockers, and less often had a bronchial mass on endoscopy.

\section{Operative Events}

The estimated median blood loss as determined from anesthesia records was $300 \mathrm{~mL}$; estimated blood loss exceeded $1000 \mathrm{~mL}$ in 10 patients. Twenty-five $(13.7 \%)$ patients received intraoperative red blood cell transfusions. Bronchial stump coverage with vascularized tissue was described in all but 3 patients and consisted in the induction group of intercostal muscle in 23 , pericardial fat in 10 , omentum in 6 , latissimus muscle in 4, and pleura in 3 . All but 8 patients were extubated in the operating room; blood loss in 3 of these was $1000 \mathrm{~mL}$ or greater. Median operating time was 290 minutes.

\section{Pathologic Results}

The histologic type of carcinoma was squamous in 95 , adenocarcinoma in 73 , large cell in 8 , adenosquamous in 6 , and bronchioalveolar in 1 . The pathologic stage is listed in Table 3. Eight patients had M1 disease as a result of either solitary brain metastasis (3 patients) or ipsilateral carcinoma of identical histologic type in a separate lobe (5 patients: adenocarcinoma 4 and adenosquamous 1). Microscopically positive margins were identified in $9(4.9 \%)$ resections.
Hilar soft tissue was positive in 5 , the perivascular margin in 2 , and the atrial margin in 1 patient. There were no grossly incomplete (R2) resections. In the induction group, 9 (19.5 $\%$ ) of 46 patients had a complete pathologic response.

\section{Mortality and Morbidity}

The overall hospital mortality was $6.0 \%(11 / 183)$. There was no hospital death during the last 5 years of the study period. Table 4 lists the procedure-specific mortality. Hospital mortality for right pneumonectomy was higher than for left pneumonectomy, but induction therapy was not associated with increased mortality. No patient with stage IV disease and 1 patient with stage IIIB (T4 N0) died.

Causes of hospital death are given in Table 5. Adult respiratory distress syndrome or postpneumonectomy pulmonary edema in 4 patients was the leading cause of death. Hospital morbidity is listed in Table 6 . A bronchopleural fistula was confirmed in 5 patients $(2.7 \%, 2$ right and 3 left $)$, of whom 1 received induction therapy and 2 died during hospitalization. The only difference in the rates of individual or combined cardiopulmonary morbidities was a higher tracheostomy rate in the induction group $(8.9 \%$ vs $1.5 \% ; P=.034)$.

\section{Multivariate Analysis}

The nonoperative and operative variables that entered in the multivariable model and predicted induction therapy were the absence of a bronchial tumor mass $(P=.0019)$,

TABLE 1. Demographic data and nonoperative risk factors

\begin{tabular}{|c|c|c|c|}
\hline Variable & $\begin{array}{c}\text { No } \\
\text { induction }\end{array}$ & $\begin{array}{c}\text { Induction } \\
\text { therapy }\end{array}$ & $\begin{array}{c}P \\
\text { value }\end{array}$ \\
\hline No. & 137 & 46 & \\
\hline Age, y (mean \pm SD & $61.9 \pm 11.5$ & $58.4 \pm 10.0$ & .0334 \\
\hline Male gender $(\%)$ & 62.8 & 60.9 & .8613 \\
\hline Hypertension (\%) & 43.8 & 39.1 & 6094 \\
\hline Diabetes $(\%)$ & 7.3 & 8.7 & .7530 \\
\hline Steroid use $(\%)$ & 5.8 & 6.5 & 1.0000 \\
\hline $\mathrm{CHF}(\%)$ & 8.8 & 0.0 & .0391 \\
\hline CAD $(\%)$ & 21.2 & 6.5 & .0247 \\
\hline $\mathrm{CAD}$ or $\mathrm{CHF}(\%)$ & 26.3 & 6.5 & .0035 \\
\hline Renal failure (\%) & 2.9 & 4.3 & .6421 \\
\hline Peripheral vascular disease $(\%)$ & 8.0 & 8.7 & 1.0000 \\
\hline Cerebrovascular accident $(\%)$ & 6.6 & 4.3 & .7331 \\
\hline Transient ischemic attack (\%) & 2.2 & 2.2 & 1.0000 \\
\hline Preoperative hematocrit \pm SD & $37.9 \pm 4.6$ & $35.2 \pm 4.1$ & $<.0001$ \\
\hline Preoperative radiotherapy $(\%)$ & 0 & 91.4 & $<.0001$ \\
\hline $\mathrm{FEV}_{1} \pm \mathrm{SD}$ & $2.13 \pm 0.71$ & $2.48 \pm 0.64$ & .0018 \\
\hline $\mathrm{FEV}_{1} \pm \mathrm{SD}(\%)$ & $70.6 \pm 19.6$ & $80.5 \pm 19.0$ & .0026 \\
\hline $\mathrm{FVC} \pm \mathrm{SD}$ & $3.02 \pm 0.96$ & $3.41 \pm 0.84$ & .0187 \\
\hline $\mathrm{DLCO} \pm \mathrm{SD}(\%)$ & $69.6 \pm 19.0$ & $78.5 \pm 19.4$ & .0721 \\
\hline \multicolumn{4}{|l|}{ Scintigraphy } \\
\hline Perfusion in remaining lung $(\%)$ & $67.5 \pm 14.0$ & $63.5 \pm 9.4$ & .1574 \\
\hline Ventilation in remaining lung ( $\%)$ & $62.7 \pm 15.0$ & $58.0 \pm 9.0$ & .1193 \\
\hline
\end{tabular}

$S D$, Standard deviation; $C H F$, congestive heart failure; $C A D$, coronary artery disease $F E V_{1}$, forced expiratory volume in 1 second; $D L C O$, carbon monoxide diffusion capacity. 
TABLE 2. Operative variables in patients with and without induction therapy

\begin{tabular}{|c|c|c|c|c|c|}
\hline \multirow[b]{2}{*}{ Variable } & \multicolumn{2}{|c|}{$\begin{array}{l}\text { No induction } \\
(n=137)\end{array}$} & \multicolumn{2}{|c|}{$\begin{array}{c}\text { Induction therapy } \\
(n=46) \\
\end{array}$} & \multirow[b]{2}{*}{$P$ value } \\
\hline & $\%$ & $\mathbf{n}$ & $\%$ & $\mathbf{n}$ & \\
\hline Mediastinoscopy & 96.4 & 132 & 93.5 & 43 & 4167 \\
\hline Bronchial tumor mass & 67.2 & 92 & 34.8 & 16 & .0002 \\
\hline Epidural pain control & 99.3 & 136 & 100.0 & 46 & 1.0000 \\
\hline Right pneumonectomy & 38.0 & 64 & 47.8 & 48 & .2976 \\
\hline Intrapericardial procedure & 43.1 & 59 & 71.1 & 33 & .0011 \\
\hline Total duration $(\min \pm \mathrm{SD})$ & $288 \pm 90$ & & $314 \pm 108$ & & .2685 \\
\hline Operative hypotension & 19.4 & & 19.6 & & 1.0000 \\
\hline Operative beta-blocker use & 7.8 & & 21.7 & & .0154 \\
\hline Operative vasopressor use & 62.8 & & 63.0 & & 1.0000 \\
\hline Extubation in OR & 95.6 & & 95.7 & & 1.0000 \\
\hline $\begin{array}{l}\text { Total blood loss } \\
\qquad(\mathrm{mL} \pm \mathrm{SD})\end{array}$ & $371 \pm 261$ & & $445 \pm 371$ & & .2087 \\
\hline $\mathrm{RBC}$ units $( \pm \mathrm{SD})$ & $0.19 \pm 0.63$ & & $0.70 \pm 1.72$ & & .0057 \\
\hline $\begin{array}{l}\text { Mean duration of } \\
\text { intubation (days } \pm \mathrm{SD})\end{array}$ & $1.16 \pm 0.44$ & & $1.13 \pm 0.34$ & & .7836 \\
\hline pT classifier & $2.40 \pm 0.64$ & & $2.11 \pm 0.61$ & & .0124 \\
\hline pN classifier & $0.82 \pm 0.64$ & & $1.25 \pm 0.89$ & & .0017 \\
\hline
\end{tabular}

$S D$, Standard deviation; $O R$, operating room; $R B C$, red blood cell; $p T p N$, pathologic T resp. N.

a higher $\mathrm{pN}$ classifier $(P=.0019)$, intrapericardial procedure $(P=.0022)$, the absence of coronary artery disease or congestive heart failure $(P=.015)$, intraoperative beta-blocker use $(P=.015)$, more units of blood transfused $(P=.016)$, and higher carbon monoxide diffusion capacity (odds ratio 1.04; $P=.017)$. Age, sex, renal disease, hypertension, $\mathrm{FEV}_{1}$, and immediate extubation did not predict induction therapy. The propensity score was entered, as a variable, in a logistic regression for hospital mortality. Induction therapy did not predict hospital mortality, after adjustment for propensity score (Table 7).

Induction therapy remained nonpredictive for hospital mortality when this model was adjusted for additional variables. Hypertension, present in $45 \%$ of survivors and only $9.1 \%$ of operative deaths $(P=.026)$, modestly lowered the odds of mortality (Table 8).

When only nonoperative or preoperative variables were entered in this model to determine the propensity score, induction therapy again failed to predict operative death.

TABLE 4. Procedure-specific mortality

\begin{tabular}{lccc}
\hline & & \multicolumn{2}{c}{ Hospital mortality } \\
\cline { 3 - 4 } Type of pneumonectomy & No. of procedures & $\%$ & No. of deaths \\
\hline Total group & 183 & 6.0 & 11 \\
Induction therapy & 46 & 4.3 & 2 \\
Resection only & 137 & 6.6 & 9 \\
Right, induction therapy & 22 & 4.5 & 1 \\
Right, resection only & 52 & 11.5 & 6 \\
Left, induction therapy & 24 & 4.2 & 1 \\
Left, resection only & 85 & 3.5 & 3 \\
\hline
\end{tabular}

TABLE 3. Pathologic stage after pneumonectomy

\begin{tabular}{lcc}
\hline & No induction & Induction therapy \\
\hline Stage I & & \\
T2 N0 & 21 & 9 \\
Stage II & 1 & 1 \\
T1 N1 & 52 & 7 \\
T2 N1 & 14 & 0 \\
T3 N0 & & \\
Stage IIIA & 16 & 0 \\
T3 N1 & 17 & 16 \\
T1-3 N2 & & \\
Stage IIIB & 10 & 1 \\
T4 N0-2 & 0 & 1 \\
T2 N3 & & 2 \\
Stage IV & 6 & 9 \\
Any M1 & &
\end{tabular}

\section{DISCUSSION}

There is disagreement concerning whether neoadjuvant therapy raises the operative risk of pneumonectomy. In contrast to several retrospective studies that found increased respiratory complications ${ }^{5}$ but no increase in mortality after induction chemotherapy, ${ }^{6,7}$ a recent prospective randomized study, Southwest Oncology Group phase II 8805, examining induction trimodality therapy, reported a higher operative mortality, in particular after right pneumonectomy. ${ }^{1}$ Other retrospective studies ${ }^{8-10}$ also reported risks for pneumonectomy that exceeded a recently reported $6 \%$ mortality of standard pneumonectomy in the Society of Thoracic Surgeons Thoracic Database. ${ }^{11}$ The preliminary analysis of intergroup trial 0139 found an early mortality of $24 \%$ after right pneumonectomy. ${ }^{12}$ These reports overlap with existing knowledge of increased operative mortality and morbidity after resection of the right lung in comparison with left-sided procedures. ${ }^{13}$ The awareness of this risk is expected to influence the choice and sequence of multimodality therapy for locally advanced lung cancer and may narrow already limited treatment options. However, the attribution of higher mortality rates to preoperative therapy is not conclusive; institutionspecific selection criteria for pneumonectomy, extent of evaluation of comorbidity, and use of surgical strategies to

TABLE 5. Causes of hospital death

\begin{tabular}{lcc}
\hline \multicolumn{1}{c}{ Cause } & No induction & Induction therapy \\
\hline Adult respiratory distress syndrome & 3 & 1 \\
Bronchopleural fistula & 2 & - \\
Myocardial infarction & 2 & - \\
Right heart failure & - & 1 \\
Pneumonia & 1 & - \\
Pulmonary hypertension & 1 & - \\
Hemorrhage & - & - \\
Ventricular fibrillation & 1 & 1 \\
\hline In 2 patients, two causes contributing to death were listed.
\end{tabular}

In 2 patients, two causes contributing to death were listed. 
TABLE 6. Hospital mortality and morbidity in patients with and without induction therapy

\begin{tabular}{|c|c|c|c|c|c|}
\hline \multirow[b]{2}{*}{ Variable } & \multicolumn{2}{|c|}{$\begin{array}{l}\text { No induction } \\
(\mathbf{n}=137)\end{array}$} & \multicolumn{2}{|c|}{$\begin{array}{l}\text { Induction therapy } \\
\quad(n=46)\end{array}$} & \multirow[b]{2}{*}{$P$ value } \\
\hline & n & $\%$ & $\mathbf{n}$ & $\%$ & \\
\hline Death & 9 & 6.6 & 2 & 4.3 & .7331 \\
\hline ARDS & 10 & 7.4 & 6 & 13.3 & .2329 \\
\hline Pneumonia & 15 & 11.0 & 7 & 15.6 & .4351 \\
\hline Reintubation & 12 & 8.8 & 5 & 11.4 & .5672 \\
\hline Pulmonary edema & 9 & 6.6 & 0 & 0.0 & .1148 \\
\hline Bronchopleural fistula & 4 & 2.9 & 1 & 2.2 & 1.0000 \\
\hline Empyema & 5 & 3.7 & 1 & 2.2 & 1.0000 \\
\hline Reoperation & 11 & 6.6 & 7 & 15.6 & .1265 \\
\hline Pulmonary embolism & 1 & 0.7 & 1 & 2.2 & .4365 \\
\hline Tracheotomy & 2 & 1.5 & 4 & 8.9 & .0343 \\
\hline Myocardial infarction & 3 & 2.2 & 0 & 0.0 & .5750 \\
\hline Ventricular fibrillation & 4 & 2.9 & 2 & 4.3 & .6394 \\
\hline Congestive heart failure & 4 & 2.9 & 1 & 2.2 & 1.0000 \\
\hline Atrial fibrillation & 34 & 25.0 & 17 & 37.8 & .1258 \\
\hline GI complications & 7 & 5.1 & 4 & 8.9 & .47 \\
\hline Neurologic events & 8 & 5.9 & 4 & 8.9 & 4963 \\
\hline $\begin{array}{l}\text { Combined cardiopulmonary } \\
\text { complications }\end{array}$ & 55 & 40.4 & 23 & 51.1 & .2278 \\
\hline
\end{tabular}

protect the bronchial stump represent important factors that are difficult to capture and compare. Finally, the avoidance of pneumonectomy and trimodality therapy may lead to higher locoregional recurrence and lower survival.

In this retrospective analysis of pneumonectomy for lung cancer, neither operative mortality nor morbidity was increased in patients who received induction therapy before pneumonectomy for lung cancer. The effects of patient selection, demonstrated by the lower age and rates of comorbidity in the induction group, are obvious and appropriate to reduce operative risk. Propensity score analysis suggests, however, that the comorbid condition itself, and not neoadjuvant therapy, imparts risk under the existing conditions of patient selection. The result of this study supports the continued use of trimodality therapy before pneumonectomy and emphasizes the importance of rigorous and careful preoperative cardiopulmonary evaluation of operative candidates and meticulous operative technique.

On the basis of our results in patients with stage IIIA N2 disease in $1991,{ }^{2}$ we have preferred and continue to recommend to combine preoperative radiation and chemotherapy for clinical stage IIIA and selected stage II disease. Absence of disease in mediastinal lymph nodes after complete resection has proved in this and the Southwest Oncology Group 8805 study (in $10 / 42$ patients, $24 \%,{ }^{2}$ vs $19 / 89$ patients, $21 \%^{1}$ ) to be the strongest predictor of long-term survival. In addition to $\mathrm{N} 2$ disease, this approach included selected patients with large hilar tumors owing to concern for positive margins at the mediastinum. The complete response rate in the present study, $19.5 \%$, is comparable with those in the
TABLE 7. Logestic regression for hospital mortality

\begin{tabular}{lclr}
\hline \multicolumn{1}{c}{ Variable } & OR & \multicolumn{1}{c}{$\mathbf{9 5} \%$ CI } & $\boldsymbol{P}$ value \\
\hline (Intercept) & 0.059 & $0.025-0.136$ & $<.0001$ \\
One unit of propensity score & 3.074 & $0.180-52.387$ & .4377 \\
Induction therapy & 0.387 & $0.048-3.123$ & .3728 \\
\hline
\end{tabular}

$O R$, Odds ratio; $C I$, confidence interval.

aforementioned studies. We have carefully selected these candidates for neoadjuvant radiochemotherapy and find our process validated. Given a selective approach to trimodality therapy, patients are not exposed to any greater operative risk by induction, a result similar to studies examining chemotherapy only. ${ }^{5-7}$ The value of multimodality therapy in the case of pneumonectomy continues to be debated as the proportion of patients in prospective randomized studies is often small so that results rarely reflect consistent selection and surgical strategy.

Right pneumonectomy with or without preoperative cytoreductive therapy remains a formidable operation with important early postoperative risks. In our study, standard pneumonectomy had a 3-fold higher hospital mortality on the right than on the left despite younger patient age, confirming the results of others. ${ }^{10,13}$ Potential causes for such imbalanced laterality risk include the greater threat of lymphatic outflow obstruction during right-sided lymph node dissections and the larger mass of the right lung. Parenchyma-sparing resections, furthermore, appear to thin out the ranks of candidates for right-sided resections more than on the left; in our earlier report of sleeve lobectomy, more than three fourths $(78 \%)$ were right-sided procedures. ${ }^{14}$ Others also have reported a higher number of right-sided sleeve resections ${ }^{15}$ and left pneumonectomies. ${ }^{13,15}$ Thus, the remaining right-sided tumors may consist of a selected group of larger, more invasive lesions in patients who may not tolerate preoperative therapy owing to comorbidity.

Our study has important limitations. First, the induction group in our study is small and may cause us to underestimate effects of induction on mortality. Further, neither we nor other investigators noted earlier include an analysis of candidates specifically rejected for this surgical procedure. Thus, the size and the survival of the rejected group are unknown, although we may infer that their survival is short. Our study also did not examine the precise tally of intraoperative and postoperative fluid management thought to be

TABLE 8. Odds of mortality

\begin{tabular}{lrll}
\hline \multicolumn{1}{c}{ Variable } & \multicolumn{1}{c}{ OR } & \multicolumn{1}{c}{$\mathbf{9 5} \%$ CI } & $\boldsymbol{P}$ value \\
\hline Renal disease & 58.637 & $3.291-1044.9$ & 0.0056 \\
Hypertension & 0.049 & $0.003-0.870$ & 0.0399 \\
Immediate extubation & 0.045 & $0.005-0.426$ & 0.0068 \\
RBC packs & 1.417 & $0.741-2.708$ & 0.2918 \\
One unit of & 8.463 & $0.126-566.8$ & 0.3194 \\
$\quad$ propensity score & & & \\
Induction therapy & 0.072 & $0.002-2.548$ & 0.1483 \\
\hline
\end{tabular}


important in the origin of adult respiratory distress syndrome and postpneumonectomy pulmonary edema; in retrospective analysis, however, the precision for these variables is weak at best. The study period further encompassed important changes in patient management, the emphasis on intraoperative pressure control ventilation and the introduction of radiation techniques limiting exposure of the contralateral lung among them, reflected in a lack of operative deaths in the last 5 years. The changes were not the subject of our analysis but require separate study.

The selection of patients for induction therapy before pneumonectomy reflected in our results is also obvious in reports of preoperative high-dose (60 Gy) mediastinal radiation and chemotherapy that were achieved with perioperative mortality rates comparable with lower, standard radiation doses. ${ }^{9,16,17}$ Median age in two of these studies was below 50 years, and mean $\mathrm{FEV}_{1}$ was above $2.4 \mathrm{~L}$ in one. Stringent preoperative evaluation, careful operative technique including protection of the bronchial stump, ${ }^{17}$ and a postoperative management dedicated to the particular risks of induction, even using elective postoperative mechanical ventilation, ${ }^{16}$ may also explain these favorable results. Other factors including surgeon experience and hospital volume ${ }^{18,19}$ have been associated with the operative outcome of pneumonectomy. Patient age, in contrast, may pose a less flexible limit to the benefits of careful selection, inasmuch as Mizushima and associates ${ }^{20}$ found an 8 -fold increase in operative mortality of pneumonectomy in patients over the age of 70 years. In our experience, patients receiving induction therapy were younger, but there was no difference in age between hospital survivors and patients who died. Patients with cardiopulmonary complications, however, were 5 years older than those without. Retrospective studies cannot be expected to disentangle the complexities of institutional selection and management, but may inform about the relative impact of risk factors.

\section{References}

1. Albain KS, Rusch VW, Crowley JJ, Rice TW, Turrisi AT 3rd, Weick JK, et al. Concurrent cisplatin/etoposide plus chest radiotherapy followed by surgery for stages IIIA (N2) and IIIB non-small-cell lung cancer: mature results of Southwest Oncology Group phase II study 8805. J Clin Oncol. 1995;13: 1880-92.

2. Choi NC, Carey RW, Daley W, Mathisen D, Wain J, Wright C, et al. Potential impact on survival of improved tumor downstaging and resection rate by preop- erative twice-daily radiation and concurrent chemotherapy in stage IIIA nonsmall-cell lung cancer. J Clin Oncol. 1997;15:712-22.

3. Mountain CF. Revisions in the International System for Staging Lung Cancer. Chest. 1997;111:1710-7.

4. Rosenbaum PR, Rubin DB. The central role of the propensity score in observational studies for causal effects. Biometrika. 1983;70:41-55.

5. Leo F, Solli P, Veronesi G, Radice D, Floridi A, Gasparri R, et al. Does chemotherapy increase the risk of respiratory complications after pneumonectomy? J Thorac Cardiovasc Surg. 2006;132:519-23.

6. Perrot E, Guibert B, Mulsant P, Blandin S, Arnaud I, Roy P, et al. Preoperative chemotherapy does not increase complications after nonsmall cell lung cancer resection. Ann Thorac Surg. 2005;80:423-7.

7. Mansour Z, Kochetkova EA, Ducrocq X, Vasilescu MD, Maxant G, Buggenhout $A$, et al. Induction chemotherapy does not increase the operative risk of pneumonectomy. Eur J Cardiothorac Surg. 2007;31:181-5.

8. Doddoli C, Barlesi F, Trousse D, Robitail S, Yena S, Astoul P, et al. One hundred consecutive pneumonectomies after induction therapy for non-small cell lung cancer: an uncertain balance between risks and benefits. J Thorac Cardiovasc Surg. 2005;130:416-25.

9. Cerfolio RJ, Bryant AS, Spencer SA, Bartolucci AA. Pulmonary resection after high-dose and low-dose chest irradiation. Ann Thorac Surg. 2005;80: 1224-30.

10. Martin J, Ginsberg RJ, Abolhoda A, Bains MS, Downey RJ, Korst RJ, et al. Morbidity and mortality after neoadjuvant therapy for lung cancer: the risks of right pneumonectomy. Ann Thorac Surg. 2001;72:1149-54.

11. Boffa DJ, Allen MS, Grab JD, Gaissert HA, Harpole DH, Wright CD. Data from The Society of Thoracic Surgeons General Thoracic Surgery database: the surgical management of primary lung tumors. J Thorac Cardiovasc Surg. 2008;135: 247-54.

12. Albain KS, Scott CB, Rusch VR, et al. Phase III comparison of concurrent chemotherapy plus radiotherapy (CT/RT) and CT/RT followed by surgical resection for stage IIIA (pN2) non-small-cell lung cancer (NSCLC): initial results from the intergroup trial 0139 (RTOG 9309). Proc Am Soc Clin Oncol. 2003;22:621 (abstr 2497).

13. Darling GE, Abdurahman A, Yi QL, Johnston M, Waddell TK, Pierre A, et al. Risk of a right pneumonectomy: role of bronchopleural fistula. Ann Thorac Surg. 2005;79:433-7.

14. Gaissert HA, Mathisen DJ, Moncure AC, Hilgenberg AD, Grillo HC, Wain JC. Survival and function after sleeve lobectomy for lung cancer. $J$ Thorac Cardiovasc Surg. 1996;111:948-53.

15. Deslauriers J, Grégoire J, Jacques LF, Piraux M, Guojin L, Lacasse Y. Sleeve lobectomy versus pneumonectomy for lung cancer: a comparative analysis of survival and sites or recurrences. Ann Thorac Surg. 2004;77:1152-6.

16. Daly BD, Fernando HC, Ketchedjian A, Dipetrillo TA, Kachnic LA, Morelli DM, et al. Pneumonectomy after high-dose radiation and concurrent chemotherapy for nonsmall cell lung cancer. Ann Thorac Surg. 2006;82:227-31.

17. Sonett JR, Suntharalingam M, Edelman MJ, Patel AB, Gamliel Z, Doyle A, et al. Pulmonary resection after curative intent radiotherapy (>59 Gy) and concurrent chemotherapy in non-small-cell lung cancer. Ann Thorac Surg. 2004;78: $1200-5$

18. Meguid RA, Brooke BS, Chang DC, Sherwood JT, Brock MV, Yang SC. Are surgical outcomes for lung cancer resections improved at teaching hospitals? Ann Thorac Surg. 2008;85:1015-24.

19. Finlayson EV, Goodney PP, Birkmeyer JD. Hospital volume and operative mortality in cancer surgery: a national study. Arch Surg. 2003;138:721-5.

20. Mizushima Y, Noto H, Sugiyama S, Kusajima Y, Yamashita R, Kashii T, et al. Survival and prognosis after pneumonectomy for lung cancer in the elderly. Ann Thorac Surg. 1997;64:193-8. 